\title{
Evaluation of Bitterness in Ragusano Cheese*
}

\author{
V. Fallico, ${ }^{1}$ P. L. H. McSweeney, ${ }^{2}$ J. Horne, ${ }^{1}$ C. Pediliggieri, ${ }^{1}$ \\ J. A. Hannon, ${ }^{2}$ S. Carpino, ${ }^{1}$ and G. Licitra ${ }^{1,3}$ \\ ${ }^{1}$ CoRFiLaC, Regione Siciliana, 97100 Ragusa, Italy \\ ${ }^{2}$ Department of Food and Nutritional Sciences, University College, Cork, Ireland \\ ${ }^{3}$ Dipartimento di Scienze Agronomiche, Agrochimiche e delle Produzioni Animali, \\ Catania University, 95100 Catania, Italy
}

\begin{abstract}
The appearance of undesirable bitter taste in Ragusano cheese was investigated by comparing the composition of 9 bitter cheeses with that of 9 reference cheeses of good quality by means of chemical, electrophoretic, and chromatographic analyses. Rates of proteolysis were significantly affected in cheeses of different quality. Primary proteolysis, as measured by $\mathrm{pH}$ 4.6-soluble $\mathrm{N}$, was significantly greater in bitter cheeses compared with reference samples. Urea-PAGE profiles showed an almost complete breakdown of caseins in bitter cheeses and the further degradation of primary peptides into smaller compounds not detectable by this technique. Cheeses with defects had significantly lower levels of secondary proteolysis as reflected by the percentage of $\mathrm{pH} 4.6$-soluble $\mathrm{N}$ soluble in $12 \%$ trichloroacetic acid and the amounts of total free amino acids. Peptides separated by reversed phase-HPLC revealed that the large and significant differences in peptide profiles of the soluble fractions between bitter and reference cheeses were mainly due to a much higher proportion of hydrophobic peptides in the former. The occurrence of bitterness in Ragusano cheese was therefore attributable to unbalanced levels of proteolysis and peptidolysis. Extensive degradation of caseins and primary peptides by activities of proteases produced large amounts of small- and mediumsized hydrophobic peptides that were not adequately removed by peptidases of microflora and therefore accumulated in cheese potentially contributing to its bitter taste. The presence of these compounds in bitter cheeses was related to high salt-in-moisture and low moisture contents that limited the enzymatic activities of microflora important in secondary proteolysis.
\end{abstract}

Received November 5, 2004.

Accepted December 28, 2004.

Corresponding author: V. Fallico; e-mail: enzofallico@corfilac.it.

*Use of names, names of ingredients, and identification of specific models of equipment is for scientific clarity and does not constitute any endorsement of the product by the authors, CoRFiLaC, University College Cork, and Catania University.
Combining salt-in-moisture and the ratio of hydrophobic-to-hydrophilic soluble peptides resulted in the best logistic partial least squares regression model predicting cheese quality. Although bitterness is known to be rarely encountered in cheese at salt-in-moisture levels $>5.0$, all of the bitter cheeses analyzed in this study had salt-in-moisture levels much greater than this value. According to the logistic model, a risk of bitterness development may exist for cheeses with a midrange (5 to $10 \%$ ) salt-in-moisture content but with an inadequate level of secondary proteolysis.

(Key words: Ragusano cheese, bitterness, hydrophobic peptide, secondary proteolysis)

Abbreviation key: EIN = 70\% ethanol-insoluble nitrogen, $\mathbf{E S N}=70 \%$ ethanol-soluble nitrogen, $\mathbf{F A A}=$ free AA, HHIP = ratio of hydrophobic-to-hydrophilic insoluble peptides, HHSP = ratio of hydrophobic-tohydrophilic soluble peptides, $\mathbf{P D O}=$ Protected Denomination of Origin, $\mathbf{p H 4 . 6 S N}=\mathrm{pH} 4.6$ acetate buffersoluble N, RP-HPLC = reversed-phase HPLC, S/M = salt-in-moisture, TCASN $=12 \%$ TCA-soluble N.

\section{INTRODUCTION}

Cheese quality is related to the development of desirable texture and flavor. Proteolysis plays a major role in determining these attributes of the ripened cheese, especially in hard- and semihard varieties (Fox et al., 1993). Proteolytic enzymes derived from rennet, milk, and microflora degrade the casein network into primary peptides that modify cheese texture. These large and medium peptides are important for the development of the desired texture but also contribute indirectly to flavor formation in cheese. Microbial peptidases degrade them to smaller peptides and free amino acids (FAA), which may be sapid and probably contribute to the background flavor of cheese. Many authors suggest that these and other compounds, contained in the low molecular weight fraction $(<500 \mathrm{Da})$, contribute to the basic taste of cheese (Engels and Visser, 1994; Engel et al., 2001). However, further conversion of FAA to various aldehydes, phenols, alcohols, acids, 
esters, and sulfur compounds is required for the development of specific cheese flavor (van Kranenburg et al., 2002).

The correct balance of sapid compounds is therefore vital to cheese quality and prevents the formation of flavor defects. For example, one of the most common off-flavors in cheese, bitterness, is caused by an excessive accumulation of bitter-tasting peptides deriving from unbalanced levels of proteolysis and peptidolysis. Bitter peptides consist of particularly hydrophobic sequences released from certain regions of $\alpha_{\mathrm{s} 1}-\mathrm{CN}$ and $\beta$-CN mainly by the action of coagulant and microbial proteinases (Visser, 1993). These hydrophobic peptides are normally produced during cheese manufacture and ripening, and give rise to slight bitter notes that are sometimes desirable in mature cheese. The simultaneous degradation to nonbitter compounds by microbial peptidases generally counterbalances this production, avoiding an excessive accumulation of bitter peptides in cheese. However, when their concentration reaches and exceeds a threshold level, because of overproduction or inadequate degradation, an undesirable bitter taste is perceived in cheese (Sousa et al., 2001). Bitterness is a major defect in Gouda (Visser, 1993), Camembert (Engel et al., 2001), Cheddar (Edwards and Kosikowski, 1983), and Gorgonzola cheeses (Gobbetti et al., 1997). Bitter off-flavor in Gouda cheese has been principally associated with the accumulation of the fragment 193-209 of $\beta$-CN, originating from its very hydrophobic C-terminus (Visser, 1993). The same peptide has been found in bitter Cheddar cheese, together with sequences released from the hydrophobic regions of residues 46-90 of $\beta$-CN as well as fragments 1-13 and 14-34 of $\alpha_{\mathrm{s} 1}-\mathrm{CN}$ (Lee et al., 1996; Sousa et al., 2001).

Ragusano cheese is a traditional raw milk cheese produced in the Hyblean plateau of Sicily (Italy), with specific and well-characterized organoleptic attributes. These sensory properties, which reflect the characteristics of the local pasture (Carpino et al., 2004) and the contribution of the natural microflora, have led to the Protected Denomination of Origin (PDO) designation to Ragusano cheese (Gazzetta Ufficiale della Comunità Europea, 1996). However, a percentage of the annual cheese production has a problem of bitterness, often associated with texture defects (open, dry, and crumbly), occasionally occurring in distinct batches. These cheeses often lack the requisites for obtaining the PDO mark and are not easily retailed, as the flavor defect of bitterness limits consumer acceptance. The objective of this study was to determine changes occurring in proteolytic profiles of bitter Ragusano cheeses by comparing their composition with that of reference cheeses of good quality (PDO cheeses) by means of chemical, electrophoretic, and chromatographic analyses.

\section{MATERIALS AND METHODS}

\section{Cheese Sampling}

Nine bitter cheeses were collected from a local market, randomly selecting 3 cheeses for each age $(4,6$, and $7 \mathrm{mo}$ ) at which Ragusano is tested to obtain the PDO mark. Bitter cheeses were selected by a group of experts trained in the recognition of textural and taste defects in cheese. The selection criterion was the presence of a strong bitter defect that, independently from the grade, made these cheeses unacceptable for consumers' tastes and therefore unmarketable. All of these cheeses had evident textural defects and were judged to lack the requisites for obtaining the PDO mark when subjected to disciplinary tests. Nine PDO cheeses with ripening times ranging from 3 to $7 \mathrm{mo}$ were selected from a farmhouse producer of Ragusano cheese for comparison with bitter ones. Cheeses were analyzed in 4 layers: rind, external, middle, and internal. The sampling pattern used was previously reported by Licitra et al. (2000).

\section{Compositional Analysis}

Grated cheese samples were analyzed in duplicate. Cheese analyses were as follows: total $\mathrm{N}$ by the Kjeldahl method (IDF, 1993), fat by the Gerber method (IDF, 1997) and NaCl by the Volhard method (AOAC, 2000). Total solids were determined using a forced-air oven drying method at $100^{\circ} \mathrm{C}$ for $24 \mathrm{~h}$ (AOAC, 2000), and $\mathrm{N}$ soluble in an acetate buffer at $\mathrm{pH} 4.6$ (pH4.6SN) and in 12\% TCA (TCASN) were determined (Bynum and Barbano, 1985) and expressed as a percentage of the total $\mathrm{N}$ content.

\section{Assessment of Proteolysis}

The $\mathrm{pH}$ 4.6-insoluble $\mathrm{N}$ of the cheeses was prepared as described by Fallico et al. (2004). Cheese $\mathrm{N}$ fractions soluble (ESN) and insoluble (EIN) in $70 \%$ ethanol were prepared from $\mathrm{pH} 4.6 \mathrm{SN}$ according to Kuchroo and Fox (1982) and freeze-dried until analyzed by reversed phase-HPLC (RP-HPLC).

The $\mathrm{pH}$ 4.6-insoluble $\mathrm{N}$ of the cheeses was analyzed by urea-PAGE using a Protean IIxi vertical slab gel unit (Bio-Rad Laboratories Ltd., Watford, UK) according to the method of Andrews (1983). The gels were stained using a modification of the method of Blakesley and Boezi (1977) with Coomassie Brilliant Blue G250. Freeze-dried aliquots of the ESN and EIN cheese extracts were analyzed by RP-HPLC as de- 
Table 1. Age-adjusted weighted means for the effects of cheese quality and layer on chemical composition of Protected Denomination of Origin (PDO) and bitter Ragusano cheeses. ${ }^{1}$

\begin{tabular}{|c|c|c|c|c|c|c|}
\hline & \multicolumn{2}{|c|}{ Quality } & \multicolumn{4}{|c|}{ Layer } \\
\hline & PDO & Bitter & Rind & Exterior & Middle & Interior \\
\hline $\mathrm{pH}$ & $5.30 \pm 0.03^{b}$ & $5.44 \pm 0.06^{\mathrm{a}}$ & $5.26 \pm 0.03^{b}$ & $5.33 \pm 0.054^{b}$ & $5.42 \pm 0.07^{\mathrm{a}}$ & $5.49 \pm 0.06^{\mathrm{a}}$ \\
\hline Moisture, \% & $37.94 \pm 2.26^{\mathrm{a}}$ & $33.16 \pm 1.45$ & $24.74 \pm 0.65^{\mathrm{c}}$ & $34.55 \pm 2.27^{\mathrm{b}}$ & $37.85 \pm 1.91^{\mathrm{a}}$ & $39.14 \pm 1.16^{\mathrm{a}}$ \\
\hline Salt, \% & $2.22 \pm 0.29$ & $4.57 \pm 0.32^{\mathrm{a}}$ & $2.78 \pm 0.29$ & $3.43 \pm 1.01$ & $3.50 \pm 0.75$ & $3.21 \pm 0.39$ \\
\hline Protein, \% & $27.76 \pm 1.08$ & $29.15 \pm 0.93$ & $34.13 \pm 0.43^{\mathrm{a}}$ & $28.93 \pm 1.01^{b}$ & $27.24 \pm 0.78^{\mathrm{c}}$ & $26.89 \pm 0.44^{\mathrm{c}}$ \\
\hline Fat in DM, \% & $47.36 \pm 1.11^{\mathrm{a}}$ & $45.00 \pm 0.80^{\mathrm{b}}$ & $46.70 \pm 0.62$ & $46.38 \pm 1.56$ & $45.75 \pm 1.0^{6}$ & $46.24 \pm 1.13$ \\
\hline $\mathrm{S} / \mathrm{M}, \%$ & $6.00 \pm 0.97^{\mathrm{b}}$ & $13.84 \pm 0.93^{\mathrm{a}}$ & $11.37 \pm 1.12^{\mathrm{a}}$ & $10.26 \pm 3.34^{\mathrm{a}}$ & $9.58 \pm 2.37^{\mathrm{ab}}$ & $8.51 \pm 1.21^{b}$ \\
\hline PH4.6SN/total N, \% & $13.35 \pm 1.72^{\mathrm{b}}$ & $17.62 \pm 2.94^{\mathrm{a}}$ & $8.28 \pm 0.55^{\mathrm{c}}$ & $14.10 \pm 3.07^{\mathrm{b}}$ & $17.60 \pm 2.54^{\mathrm{a}}$ & $19.74 \pm 2.26^{\mathrm{a}}$ \\
\hline TCASN/total N, \% & $11.49 \pm 1.38$ & $13.36 \pm 2.06$ & $6.28 \pm 0.31^{\mathrm{c}}$ & $11.26 \pm 1.71^{\mathrm{b}}$ & $14.22 \pm 1.83^{\mathrm{a}}$ & $16.01 \pm 1.33^{\mathrm{a}}$ \\
\hline TCASN/pH4.6SN, \% & $86.54 \pm 3.35^{\mathrm{a}}$ & $77.34 \pm 4.65^{\mathrm{b}}$ & $77.65 \pm 2.41$ & $82.24 \pm 7.55$ & $81.59 \pm 3.76$ & $83.68 \pm 3.42$ \\
\hline Total FAA $(\mathrm{mg} / \mathrm{g}), \%$ of total $\mathrm{N}$ & $20.93 \pm 3.01^{\mathrm{a}}$ & $16.18 \pm 1.94^{\mathrm{b}}$ & $12.71 \pm 0.79^{\mathrm{b}}$ & $18.44 \pm 3.97^{\mathrm{a}}$ & $19.68 \pm 3.26^{\mathrm{a}}$ & $20.05 \pm 1.88^{\mathrm{a}}$ \\
\hline
\end{tabular}

a,b,c Means sharing common superscripts were not significantly different $(P<0.05)$.

${ }^{1}$ Protein $=$ total $\mathrm{N} \times 6.38 ; \mathrm{S} / \mathrm{M}=[(\mathrm{NaCl}) /($ moisture content $)] \times 100 ; \mathrm{pH} 4.6 \mathrm{SN} /$ total $\mathrm{N}=\mathrm{pH} 4.6$ acetate buffer-soluble $\mathrm{N}$ as a percentage of total N; TCASN/total $\mathrm{N}=125$ TCA-soluble $\mathrm{N}$ as a percentage of total $\mathrm{N}$; TCASN/pH4.6SN $=12 \%$ TCA-soluble $\mathrm{N}$ as a percentage of $\mathrm{pH} 4.6$ acetate buffer-soluble N; FAA = free amino acids.

scribed by Lynch et al. (1996). Individual FAA were analyzed in the pH4.6SN fraction of the cheeses as described by Fenelon et al. (2000).

\section{HPLC Peak Areas}

Total peak areas were calculated from each chromatogram and divided into 3 groups representing 3 different categories of compounds, as reported by other authors (Lau et al., 1991; Gonzalez de Llano et al., 1995). Most of the FAA, except Phe and Trp, elute in the first $10 \mathrm{~min}$. Thus, the first area was made up of the area under peaks eluting from 0 to $10 \mathrm{~min}$. Hydrophilic and hydrophobic peptides were represented by the total peak areas eluting between 10 and $35 \mathrm{~min}$, and eluting after $35 \mathrm{~min}$, respectively. Ratios of hydrophobic to hydrophilic peptides were calculated from the latter 2 areas.

\section{Statistical Analyses}

A 2-way weighted analysis of covariance (ANCOVA) model was used to assess the effects of cheese quality and layer on 9 chemical variables and total FAA. Cheese quality and layer were treated as fixed main effects. Sums of squares and effect means were weighted by the contribution of each position to the total weight of the cheeses, described earlier by Fallico et al. (2004). To eliminate the effects of differences in the ripening time between the PDO and bitter cheeses, sums of squares and means were linearly adjusted for this variable by treating it as a random covariate in the model. Percentage peak areas under the HPLC chromatograms of the ESN and EIN cheese fractions, as well as the ratios of hydrophobic to hydrophilic peptides were analyzed using a nearly identical analysis of covariance design, which differed from that described above only by the fact that no weighting variable was used.

A principal components analysis solution was calculated from the correlation matrix of the ripening timeadjusted residuals associated with the 9 chemical variables, FAA, and ratios of hydrophobic to hydrophilic peptide areas from ESN and EIN chromatograms. Logistic partial least squares regression (Bastien et al., 2005) was used to model the probability of a cheese belonging to the PDO category from binary combinations of the same 12 variables. The binary combination that resulted in the best partial least squares fit (largest max-rescaled $\mathrm{R}^{2}$ value) in the fewest iterations is reported below.

\section{RESULTS AND DISCUSSION}

\section{Chemical Composition}

Weighted means for the chemical composition and total FAA in bitter and PDO cheeses are shown in Table 1 as functions of cheese quality group and layer. All but 2 (protein and percentage of total $\mathrm{N}$ soluble in $12 \%$ TCA) of these variables differed significantly ( $P$ $<0.05$ ) between cheese quality groups. Surprisingly, bitter cheeses were less acidic and had 2-fold concentrations of salt and salt-in-moisture (S/M) compared with their good quality counterparts. The development of bitterness in cheese is generally associated with more acidic $\mathrm{pH}$ values and reduced levels of $\mathrm{S} / \mathrm{M}(<5 \%)$, factors that positively affect the retention and activity of coagulant in the curd (Sousa et al., 2001). Residual chymosin is the principal proteinase in many cheese varieties and is considered to play a major role in the release of bitter peptides from the extremely hy- 
drophobic regions of $\beta$-CN (Carrera et al., 1999). The lowest moisture and fat-in-DM contents of cheeses with defects related well instead with the appearance of bitterness. Decreasing moisture, via a lowering of water activity, reduces the activities of microbial peptidases that should degrade the bitter peptides; hence, these accumulate in cheese. Further, the lower the fat content in cheese, the higher the risk for bitterness being perceived, due to the reduced opportunity for hydrophobic peptides to dissolve into and be masked by the fat phase (Sousa et al., 2001).

In terms of proteolysis, bitter cheeses had significantly higher levels of $\mathrm{pH} 4.6 \mathrm{SN}$, coupled to significantly lower ratios of TCASN to $\mathrm{pH} 4.6 \mathrm{SN}$ and significantly lower concentrations of total FAA (all $P<$ 0.05 ). The variable $\mathrm{pH} 4.6 \mathrm{SN}$ is an index of overall proteolysis in cheese, as it contains both large- and medium-sized peptides produced by chymosin and plasmin, and small-sized peptides, FAA, and other minor nitrogenous compounds produced by microbial enzymes; this latter fraction is quantified by TCASN (Fox et al., 1993). Bitter cheeses displayed a larger extent of casein hydrolysis to large- and medium-sized peptides by the action of chymosin and plasmin, but a less efficient activity of microbial peptidases in degrading them to smaller peptides and amino acids than the reference samples. Profiles of individual amino acids of PDO cheeses (results not shown) reflected those previously reported (Fallico et al., 2004). Glutamic acid was the most abundant amino acid at all times and, together with Lys and Leu, accounted for about 50\% of total FAA. Although several amino acids may taste bitter (Molina et al., 1999; Sousa et al., 2001), cheeses with defects had lower levels for each individual FAA than PDO samples. Development of bitterness in Ragusano cheese could not be thus associated with increased amounts of bitter-tasting amino acids exceeding their taste thresholds.

Rind-to-core related differences among chemical variables and FAA were consistent with previously reported results (Fallico et al., 2004). Cheeses had higher moisture contents, lower S/M and protein contents, and became less acidic across the rind-to-core gradient (all $P<0.05$ ). Three of the 4 proteolytic measures (pH4.6SN, TCASN, and FAA) increased significantly from rind to core as S/M contents decreased and moisture increased. These trends were in keeping with previous findings regarding the relationships between moisture, salt, and levels of proteolysis. Salt on a total weight basis and fat-in-DM did not differ significantly from rind to core $(P>0.05)$, but salt contents did reach a peak near cheese centers, consistent with previous findings (Guinee and Fox, 1984; Fallico et al., 2004).
Results of composition analysis suggested that the high S/M and low moisture contents of bitter cheeses might have influenced the microflora of cheese, lowering the activities of peptidases important in secondary proteolysis. This led to an accumulation of smalland medium-sized peptides, especially near cheese centers where S/M levels were low enough and moisture levels high enough for primary proteolysis to occur at significant levels. The accumulation of these peptides potentially caused the development of bitter tastes in Ragusano cheese. Similar accumulations did not occur in PDO cheeses due (presumably) to different microflora and peptidase activities. The fact that the proportion of pH4.6SN made up of small- and mediumsized peptides (TCASN) was consistently 10 to $14 \%$ higher in PDO cheeses than in bitter ones is supportive of this hypothesis.

\section{Electrophoretic Analysis}

Primary proteolysis in bitter and PDO Ragusano cheeses after 4, 6, and 7 mo of age was compared by urea-PAGE analysis of the $\mathrm{pH} 4.6$-insoluble $\mathrm{N}$ fraction (Figure 1). The extent of casein degradation was largely affected by cheese layer and age, independently of cheese quality. Increasing levels of proteolysis were found in the innermost layers and throughout ripening, in agreement with previous findings (Fallico et al., 2004). Cheese quality appeared to exert the greatest influence on patterns of proteolysis, affecting both the extent and type of casein hydrolysis. Bitter cheeses exhibited a larger and more extensive degradation of caseins than their good quality counterparts, leading to the production of a greater amount of large- and medium-sized peptides. In addition, the activities of proteases on caseins appeared to be differently regulated depending on cheese quality.

Plasmin action on $\beta$-CN produced the $\beta$-CN (f29-209) ( $\gamma_{1}$-CN), $\beta$-CN (f106-209) ( $\gamma_{2}$-CN), and $\beta$-CN (f108-209) $\left(\gamma_{3}-\mathrm{CN}\right)$ peptides (Sousa et al., 2001), present at similar levels in both cheese types after 4 mo of age. A minor activity on $\beta$-CN was instead exerted by chymosin in bitter cheeses at that time, resulting in low level production of the primary peptide $\beta$-CN (f1-192) ( $\beta$-I). This fragment is generally produced in large amounts in Ragusano cheese (Fallico et al., 2003b; 2004), as shown here in the electrophoretograms of PDO cheeses. The greatest breakdown of $\beta$-CN in 4 -mo-old bitter cheeses also resulted in highest levels of 3 peptides moving slower than $\gamma$-CN. These fragments were shown to be produced from $\beta$-CN by the action of plasmin or microbial proteinases with a trypsin-like activity (Fallico et al., 2003a). Peptide profiles of bitter cheeses displayed a larger degradation of $\alpha_{\mathrm{s} 1}-\mathrm{CN}$ compared 


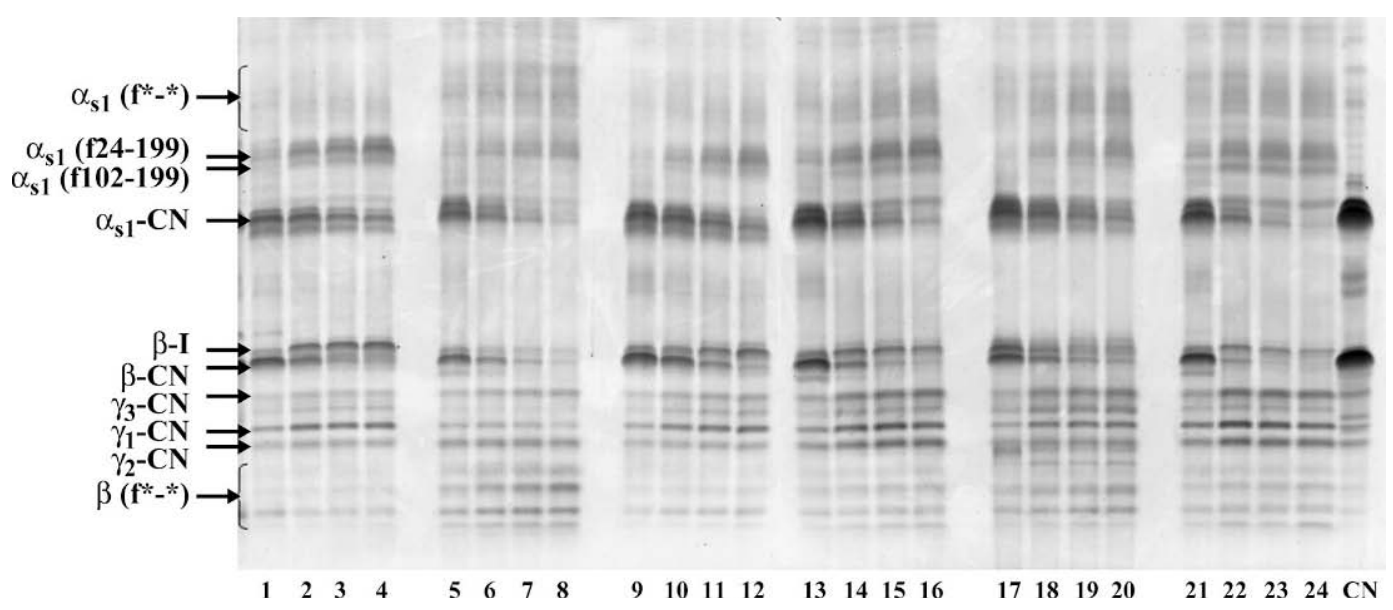

Figure 1. Urea-PAGE ( $\mathrm{pH}$ 8.6) of the $\mathrm{pH}$ 4.6-insoluble $\mathrm{N}$ fraction from selected layers (rind, external, middle, internal) of Protected Denomination of Origin (PDO) Ragusano cheese after 4 (lanes 1 to 4), 6 (lanes 9 to 12), and 7 (lanes 17 to 20) mo of age compared with those of bitter Ragusano cheese after 4 (lanes 5 to 8), 6 (lanes 13 to 16), and 7 (lanes 21 to 24) mo of age. Whole bovine casein (CN) was used as reference standard.

with those of PDO cheeses, resulting in a higher number of peptides moving faster than native casein. These fragments were shown to be mainly products of proteolysis of $\alpha_{\mathrm{s} 1}-\mathrm{CN}$ (McSweeney et al., 1993; Fallico et al., 2003a) due to rennet action. Residual chymosin activity in Ragusano cheese typically gives rise to the early production of the primary peptide $\alpha_{\mathrm{s} 1}$ - CN (f24199) $\left(\alpha_{\mathrm{s} 1}-\mathrm{I}\right)$ (Fallico et al., $\left.2003 \mathrm{~b}\right)$ and its complementary peptide $\alpha_{\mathrm{s} 1}-\mathrm{CN}$ (f1-23), which is soluble under the staining conditions of the gel. The $\alpha_{\mathrm{s} 1}$-I peptide is then hydrolyzed at the bond $\mathrm{Leu}_{101}-\mathrm{Lys}_{102}$ by further action of chymosin, producing the low mobility $\alpha_{\mathrm{s} 1}$-CN (f102199) (Fallico et al., 2004), as reported in other cheese varieties (Sousa et al., 2001). Bitter cheeses had lesser amounts of $\alpha_{\mathrm{s} 1}$-I and $\alpha_{\mathrm{s} 1}-\mathrm{CN}$ (f102-199) but a larger number of high-mobility peptides than PDO cheeses. These fragments probably derived from hydrolysis of $\alpha_{\mathrm{s} 1}$-I by chymosin (Fox and McSweeney, 1996), revealing an intense activity of coagulant in cheeses with defects. Mayer (2001) found similar urea-PAGE patterns in bitter processed cheeses, showing very low levels of native caseins but many $\gamma$-CN and other peptides with high electrophoretic mobility. Comparing the electrophoretograms of bitter and PDO cheeses after 6 and 7 mo of age resulted in similar findings to those observed in 4-mo-old cheeses. Caseins were always more degraded in bitter cheeses with a greater accumulation of primary peptides than in PDO cheeses. $\beta$-Casein appeared to be more susceptible to chymosin action at these times than before in bitter cheeses. Its largest degradation (and almost complete hydrolysis in the inner cheese layers) was indeed associated with increased levels of the chymosin-derived $\beta$-I peptide.
The electrophoretic patterns showed faster rates of primary proteolysis in bitter cheeses compared with good quality ones, in keeping with the significantly higher contents of $\mathrm{pH} 4.6 \mathrm{SN}$ found in bitter cheeses (Table 1). Intense protease activities from residual coagulant, milk, and cheese microflora caused an extensive breakdown of caseins to large peptides and their subsequent rapid degradation to smaller products, which are mostly soluble and thus not detectable on the gel using conventional staining (Mayer, 2001). Many of these peptides might derive from the highly hydrophobic regions of $\alpha_{\mathrm{s} 1}-\mathrm{CN}$ and $\beta$-CN and could contribute to the development of bitterness in Ragusano cheese. For example, the short peptide $\beta$-CN (f193-209) is formed in Ragusano cheese with the production of the complementary $\beta$-I peptide by chymosin. This peptide is released from the very hydrophobic Cterminus of $\beta$-CN and has been associated with bitterness in many cheese varieties (Visser, 1993; Sousa et al., 2001). Hydrolysis products of $\alpha_{\mathrm{s} 1}$-CN (f1-23), which is formed rapidly in Ragusano cheese together with the complementary $\alpha_{\mathrm{s} 1}$-I peptide, were found to contribute to bitterness in Cheddar cheese (Lee et al., 1996; Broadbent et al., 2002).

Salt content in bitter cheeses was twice that in PDO cheeses, probably resulting from excessive brining times used for the former. Salt has been reported to influence the rate of proteolysis in cheese by differently affecting the activities of the proteases involved. Coagulant activity on $\beta$-CN is significantly influenced by variations of the salt content, being reduced by $5 \% \mathrm{~S} /$ $\mathrm{M}$ and completely inhibited in the presence of $10 \% \mathrm{~S} /$ M (Fox and Walley, 1971), whereas the degradation of $\alpha_{\mathrm{s} 1}-\mathrm{CN}$ is affected to a lesser extent (Mulvihill and 
Fox, 1979). Conversely, salt concentration was found to positively influence plasmin activity on $\beta$-CN (Kelly et al., 1996; Kristiansen et al., 1999). The above findings might explain the differences found between bitter and good quality cheeses in the patterns of casein proteolysis related to chymosin and plasmin activities. The highest salt contents in bitter cheeses did not appreciably affect chymosin action on $\alpha_{\mathrm{s} 1} \mathrm{CN}$, leading to a large accumulation of the related hydrolysis products, and mostly reduced its activity on $\beta$-CN. However, chymosin-induced proteolysis, mainly on $\beta$-CN, appeared to be increased in bitter cheeses at 6 and 7 mo of age despite the high salt contents. This was probably due to a major effect of ripening time on overall cheese proteolysis. In a previous work, we found strong positive, linear relationships between ripening time and proteolysis in Ragusano cheese, indicating that casein hydrolysis continued at least up to 7 mo of ripening even in the presence of relatively low moisture and high S/M contents (Fallico et al., 2004). Although the salt concentration in bitter cheeses was very unfavorable for rennet-induced proteolysis, a slow but gradual accumulation of bittertasting peptides released from the very hydrophobic regions of $\beta$-CN probably resulted in threshold value for bitter perception being exceeded. Plasmin action was conversely favored by high salt concentrations, being the extensive degradation of $\beta$-CN related to large production of $\gamma-\mathrm{CN}$ and the 3 slowest moving peptides. Moreover, the high $\mathrm{pH}$ values in bitter cheeses probably favored the activity of plasmin on $\beta$ CN. Creamer (1985) found that increasing cheese $\mathrm{pH}$ influenced the degree of hydration and aggregation of $\beta$-CN resulting in a modified susceptibility to hydrolysis by proteases. Similarly, Kelly et al. (1996) reported a positive relationship between the amount of $\gamma$-CN and $\mathrm{pH}$ values in Cheddar-type cheese.

\section{RP-HPLC Analysis of EIN and ESN}

Although the water-insoluble portion of cheese is considered flavorless, the complementary soluble fraction contributes significantly to cheese flavor (Sousa et al., 2001). Bitterness is most intense in this latter fraction, which is considered approximately equivalent to $\mathrm{pH} 4.6 \mathrm{SN}$ in cheeses where $\mathrm{pH}$ does not increase considerably during ripening (Kuchroo and Fox, 1982). Ragusano cheese extracts soluble at $\mathrm{pH} 4.6$ were further fractionated using $70 \%$ ethanol and analyzed by RP-HPLC. Chromatograms of the EIN and ESN fractions from 4 layers of bitter and PDO cheeses at selected ages are shown in Figures 2 and 3, respectively. Peptide profiles confirmed the results of the chemical and electrophoretic analyses. A much larger quantity of peptides was found in the EIN and ESN chromatograms of bitter cheeses compared with those of PDO cheeses, mostly evident at 4 mo of age. These findings related well with the data for $\mathrm{pH} 4.6 \mathrm{SN}$ and TCASN (Table 1); this latter fraction contains similar peptides to those in the ESN fraction (Kuchroo and Fox, 1982). All of the peaks, accounting for the differences between bitter and reference cheeses, eluted in the region between 30 and 60 min and therefore corresponded to hydrophobic peptides. According to several authors (Lau et al., 1991; Gonzalez de Llano et al., 1995), RPHPLC chromatograms may be divided into 3 zones, with most of the FAA (except Phe and Trp) eluting from 0 to $10 \mathrm{~min}$, the hydrophilic peptides in the 10 to 35 min interval, and the hydrophobic peptides usually eluting in the interval 35 to $80 \mathrm{~min}$. This latter fraction is the peptide portion considered responsible for bitter taste in cheese (Habibi-Najafi and Lee, 1996). Bitter fractions, isolated by gel filtration chromatography of the water-soluble extract of aged Cheddar cheese, are composed of peptides with long elution times on RPHPLC (Cliffe et al., 1993). However, concentration of bitter peptides must exceed a certain threshold value before bitterness is perceived in cheese. Several authors have used RP-HPLC to quantify the proportion of hydrophobic-to-hydrophilic peptides in cheese and relate this measure to the appearance of the bitterness defect (Lau et al., 1991; Gomez et al., 1997; Carrera et al., 1999). Reversed phase-HPLC chromatograms of bitter and PDO cheeses were divided into 3 zones according to the above criteria, and the corresponding percentage peak areas are shown in Table 2. Mean percentage areas in the FAA and hydrophobic peptide regions of chromatograms differed significantly between PDO and bitter cheeses between ESN and EIN fractions (all $P<0.05$ ). A much larger proportion of both fractions eluted at less than $10 \mathrm{~min}$ in PDO cheeses than in bitter ones, in keeping with the significantly higher amounts of FAA found in the former (Table 1). Differences of nearly equal magnitude were present in the hydrophobic region of the chromatograms, but in the opposite direction. Differences among peak areas in the hydrophilic region of the chromatograms, on the other hand, were not significant ( $P$ $>0.05$ ) and accounted for 20 to $25 \%$ of total peak areas in both PDO and bitter cheeses. The large and significant differences in hydrophobic-to-hydrophilic peak area ratios between PDO and bitter cheeses $(P<0.05)$ were therefore mainly functions of differences in hydrophobic peak areas, which accounted for much larger proportions of total peak areas in the bitter cheeses. Similarly, Mayer (2001) found a much higher proportion of hydrophobic peptides in the water-soluble frac- 

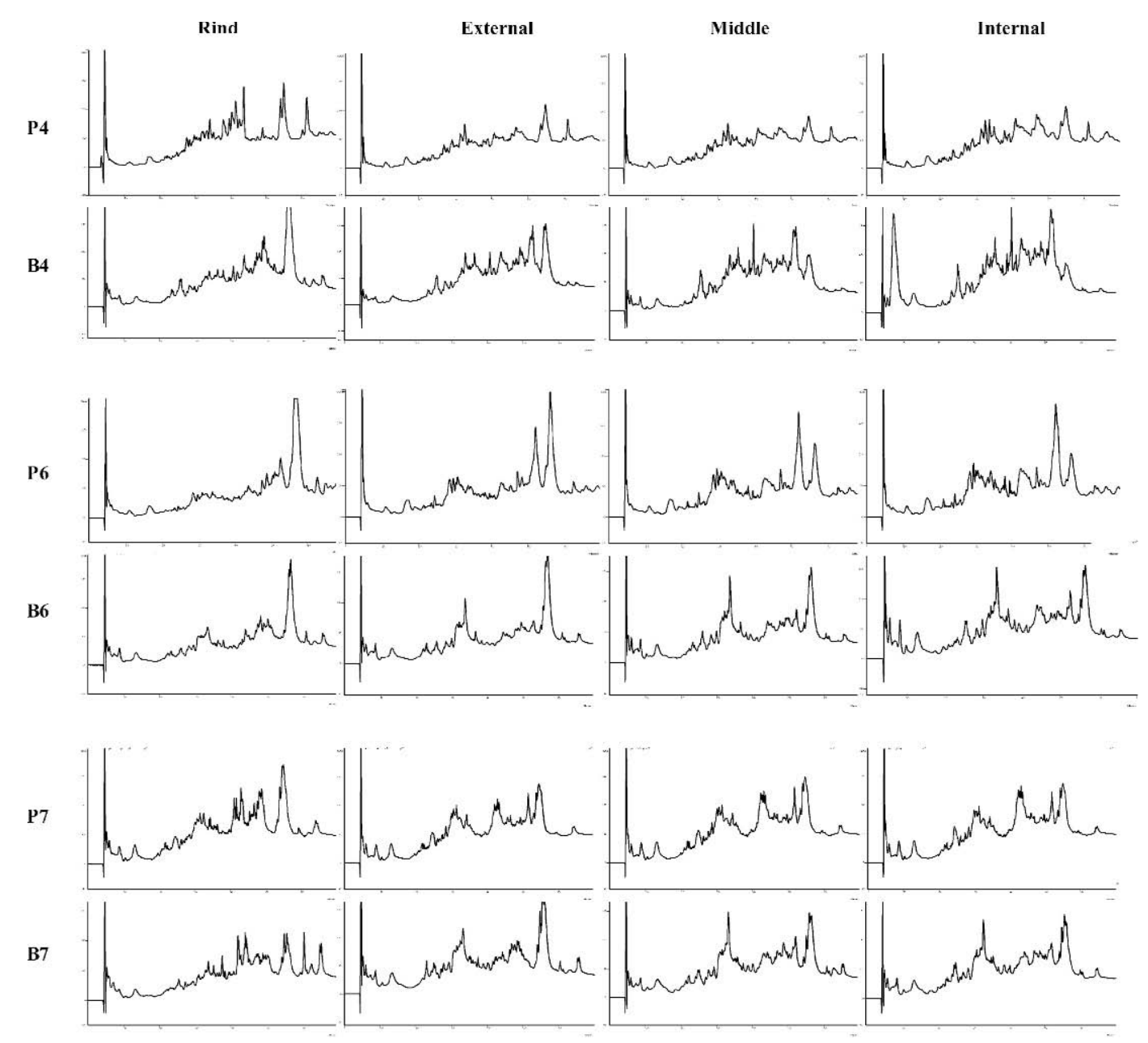

Figure 2. Reversed phase-HPLC chromatograms of the 70\% ethanol-insoluble peptides from selected layers of Protected Denomination of Origin (P) and bitter (B) Ragusano cheese after 4, 6, and 7 mo of age.

tion of bitter processed cheeses compared with the reference samples of good quality.

Differences from rind to core associated with the EIN and ESN peak areas mainly separated the rind layers from the rest of the cheeses. Only the hydrophobic-to-hydrophilic ratios of the ESN differed significantly, decreasing from rind to core as more proteolysis occurred toward the cheese center. Conversely, hydrophilic and hydrophobic regions of EIN fractions varied significantly by about $10 \%$ from rind to core in opposite directions, resulting in a significant rind-to-core decrease in hydrophobic-to-hydrophilic ratios (all $P<$ $0.05)$.

These results suggested a strong relationship between bitterness and the level of medium- and smallsized hydrophobic peptides in Ragusano cheese, in accordance with previous reports. Bitterness in dairy products has been mainly related to peptides having average hydrophobicity (>1400 cal/residue) and molec- ular weight from 100 to $6000 \mathrm{Da}$ (Habibi-Najafi and Lee, 1996). The bitterness defect in Camembert cheese was attributed to small peptides whose mass distribution was established by HPLC-mass spectroscopy as 400 to 3000 Da (Engel et al., 2001). However, peptides with a mean molecular weight less than 1000 Da were found in bitter fractions isolated from Cheddar cheese (Lemieux et al., 1989).

\section{Multivariate Analyses}

Two Varimax-rotated factors explaining slightly more than $70 \%$ of between-sample variation were extracted from principal components analysis. The rotated components explained nearly equal amounts of total variation (38.1 and $32.1 \%$, respectively) among the samples. A third component had an unrotated eigen value $>1$, but explained a trivial amount of variation $(9.8 \%)$ compared with the first 2 components, and 

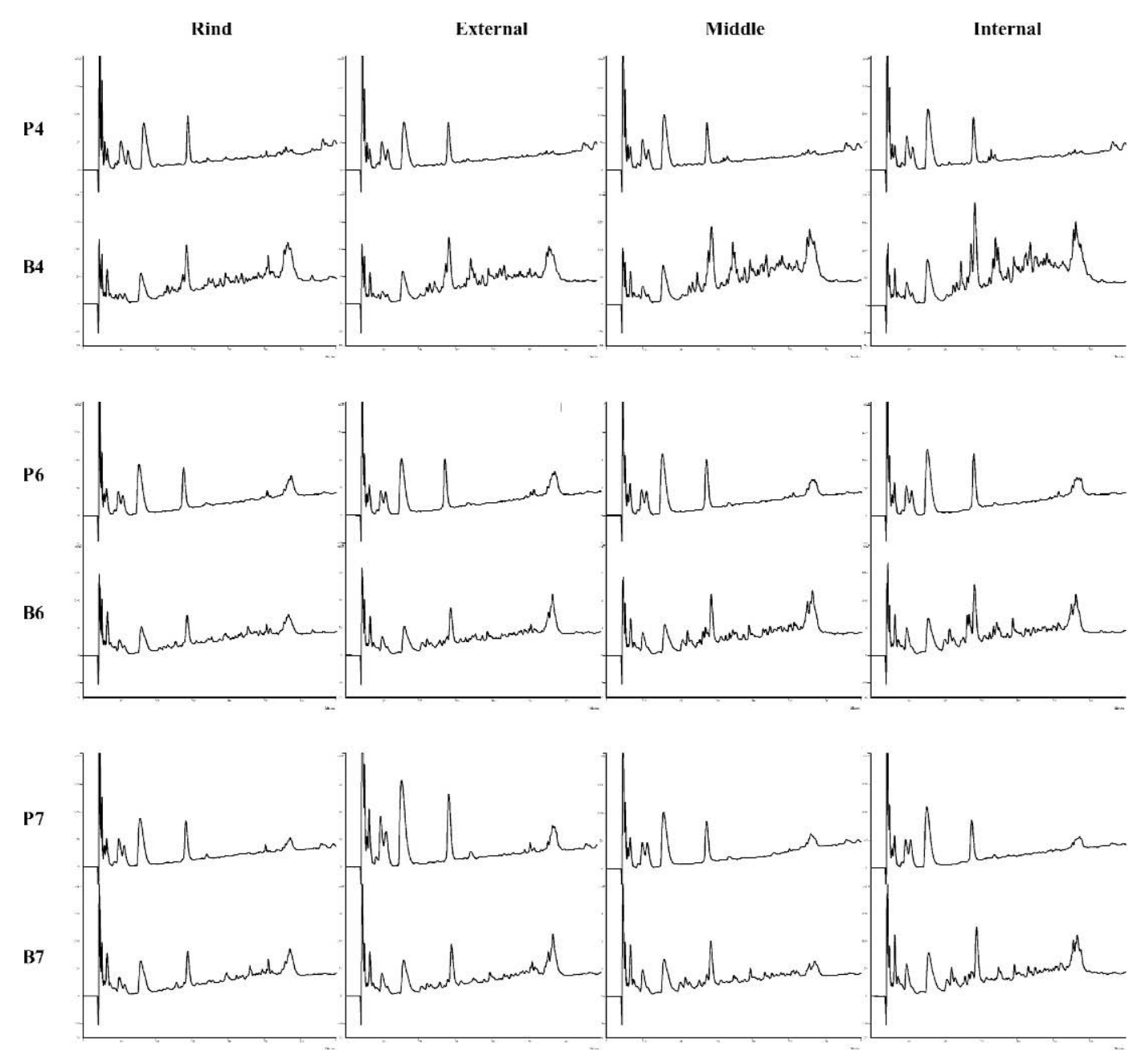

Figure 3. Reversed phase-HPLC chromatograms of the 70\% ethanol-soluble peptides from selected layers of Protected Denomination of Origin (P) and bitter (B) Ragusano cheese after 4, 6, and 7 mo of age.

Table 2. Effects of cheese quality and layer on percentage peak areas under the reversed phase-HPLC chromatograms of the ESN and EIN fractions of Protected Denomination of Origin (PDO) and bitter Ragusano cheeses. ${ }^{1}$

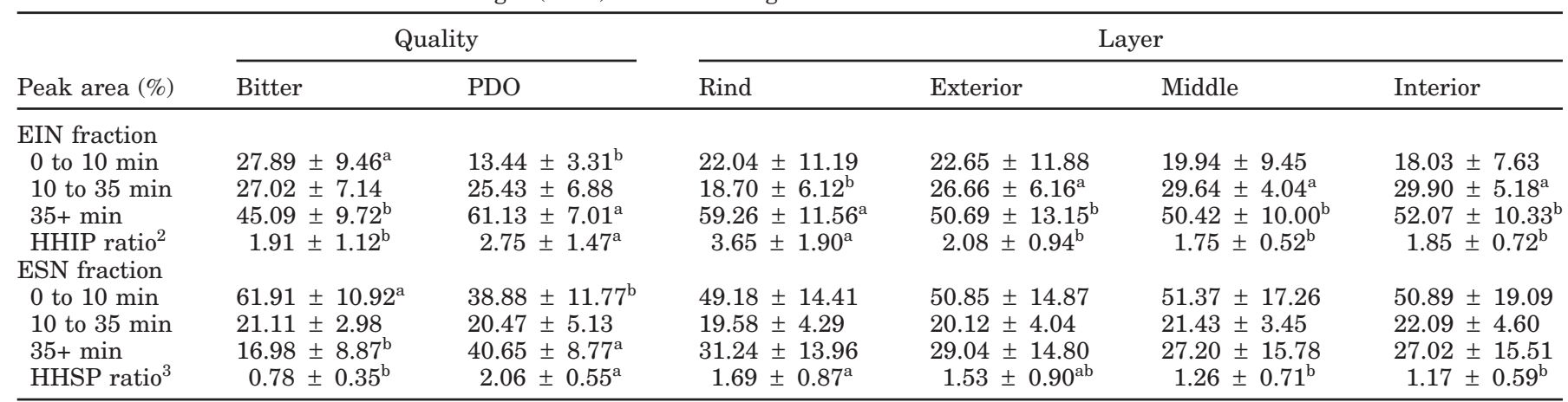

${ }^{\mathrm{a}, \mathrm{b}}$ Means sharing common superscripts were not significantly different $(P<0.05)$.

${ }^{1} \mathrm{ESN}=70 \%$ Ethanol-soluble $\mathrm{N}$; $\mathrm{EIN}=70 \%$ ethanol-insoluble $\mathrm{N} ; 0$ to $10 \mathrm{~min}, 10$ to $35 \mathrm{~min}$, and $35+$ min = nitrogenous compounds (free amino acids) eluting within the 0 to $10 \mathrm{~min}$ interval, the 10 to $35 \mathrm{~min}$ interval, and from $35 \mathrm{~min}$ to the end of the chromatogram, respectively.

${ }^{2} \mathrm{HHIP}$ ratio $=$ ratio of hydrophobic-to-hydrophilic insoluble peptides.

${ }^{3}$ HHSP ratio $=$ ratio of hydrophobic-to-hydrophilic soluble peptides. 


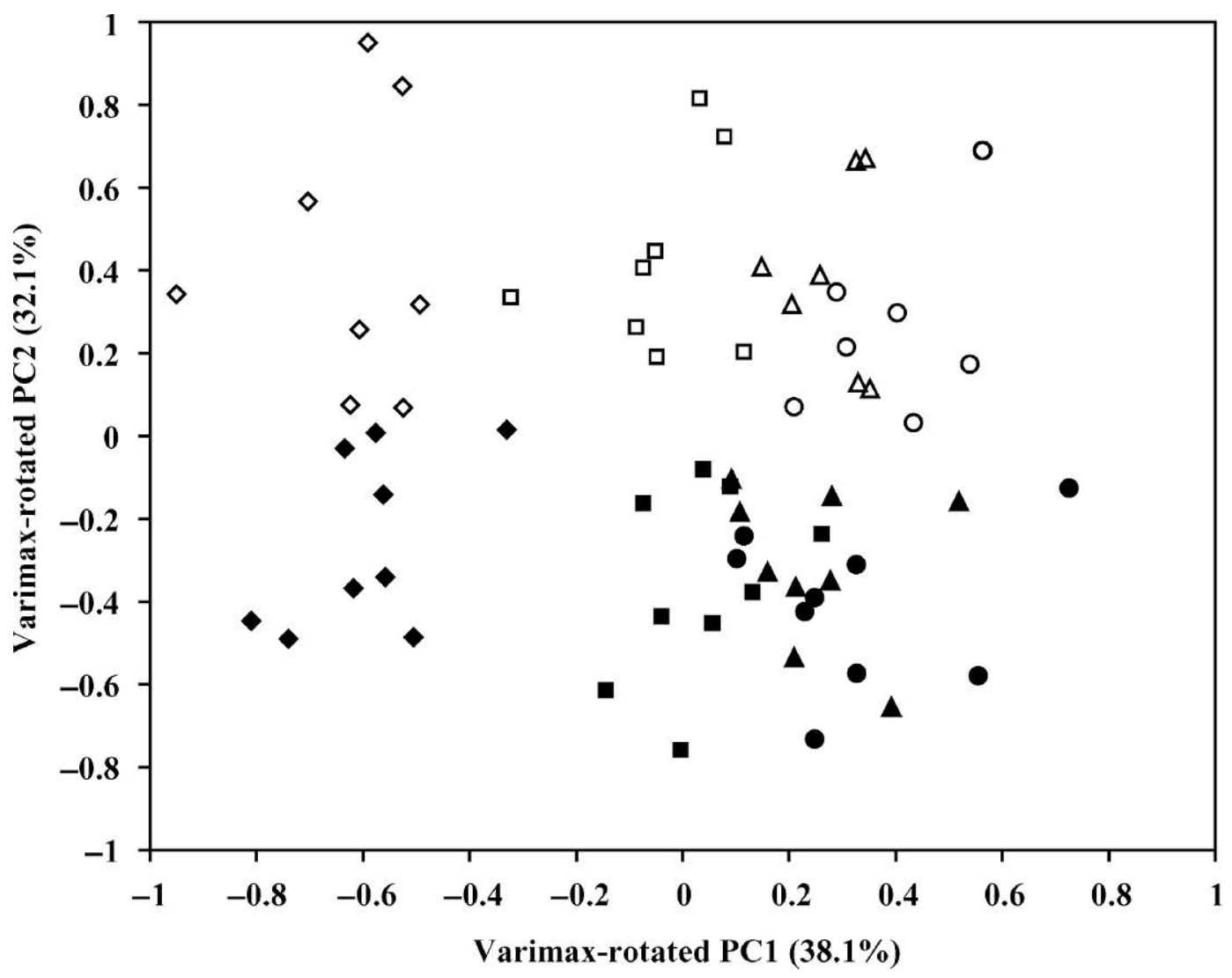

Figure 4. Score plot obtained by principal components analysis (PCA) of data from gross composition and ratios of hydrophobic-tohydrophilic insoluble (HHIP) and hydrophobic-to-hydrophilic soluble (HHSP) peptides from reversed phase-HPLC chromatograms from selected layers $(\diamond \diamond=$ rind, $\square \mathbf{\square}=$ external, $\Delta \mathbf{\Lambda}=$ middle, $\bigcirc \mathbf{~ = ~ i n t e r n a l ) ~ o f ~ b i t t e r ~ ( o p e n ~ s y m b o l s ) ~ a n d ~ P r o t e c t e d ~ D e n o m i n a t i o n ~ o f ~ O r i g i n ~}$ (solid symbols) Ragusano cheese at different ages (3, 4, 6, and 7 mo).

contained no high-dependent variable loadings. Therefore, this factor was excluded from the rotated solution. The rotated principal components effectively separated samples by cheese layer and quality group (Figure 4). The largest separation occurred between rind and other portions of the cheeses on PC1. This separation was $100 \%$ efficient (i.e., there were no overlaps between the 2 groups), although one exterior sample almost overlapped with one rind sample. Variables having the highest loadings on PC1 included moisture, protein, pH4.6SN, TCASN, and FAA; of these, all but protein loaded positively (Table 3 ). The high positive loadings of pH4.6SN, TCASN, and FAA and the high negative loading of hydrophobic-to-hydrophilic insoluble peptide ratios (HHIP) on this axis indicated that proteolysis was less intense in the rinds compared with layers nearer cheese centers. Differences among the 3 internal layers followed a predictable pattern along PC1. However, these differences were very small compared with the differences between rinds and the 3 internal layers. These results showed that proteolysis
Table 3. Significant correlations between gross composition and ratios of hydrophobic-to-hydrophilic insoluble (HHIP) and soluble (HHSP) peptides from reversed phase-HPLC chromatograms and principal components, $\mathrm{PC} 1$ and PC2. ${ }^{1}$

\begin{tabular}{lrr}
\hline & \multicolumn{1}{c}{ PC1 } & \multicolumn{1}{c}{ PC2 } \\
\hline pH & 0.577 & 0.470 \\
Moisture, \% & 0.909 & 0.002 \\
Salt, \% & 0.006 & 0.897 \\
Protein, \% & -0.853 & -0.065 \\
Fat in DM, \% & -0.049 & -0.642 \\
S/M, \% & -0.550 & 0.767 \\
pH4.6SN/total N, \% & 0.649 & 0.675 \\
TCASN/total N, \% & 0.788 & 0.522 \\
TCASN/pH4.6SN, \% & 0.330 & -0.643 \\
Total FAA (mg/g), \% of total N & 0.777 & -0.244 \\
HHIP ratio & -0.694 & 0.065 \\
HHSP ratio & -0.476 & 0.728 \\
\hline
\end{tabular}

${ }^{1}$ Protein $=$ total $\mathrm{N} \times 6.38 ; \mathrm{S} / \mathrm{M}=[(\mathrm{NaCl}) /($ moisture content $)] \times 100 ;$ $\mathrm{pH} 4.6 \mathrm{SN} /$ total $\mathrm{N}=\mathrm{pH} 4.6$ acetate buffer-soluble $\mathrm{N}$ as a percentage of total N; TCASN/total $\mathrm{N}=125$ TCA-soluble $\mathrm{N}$ as a percentage of total $\mathrm{N}$; TCASN $/ \mathrm{pH} 4.6 \mathrm{SN}=12 \% \mathrm{TCA}$-soluble $\mathrm{N}$ as a percentage of pH 4.6 acetate buffer-soluble N; FAA = free amino acids; HHIP ratio = ratio of hydrophobic-to-hydrophilic insoluble peptides; HHSP ratio $=$ ratio of hydrophobic-to-hydrophilic soluble peptides. 


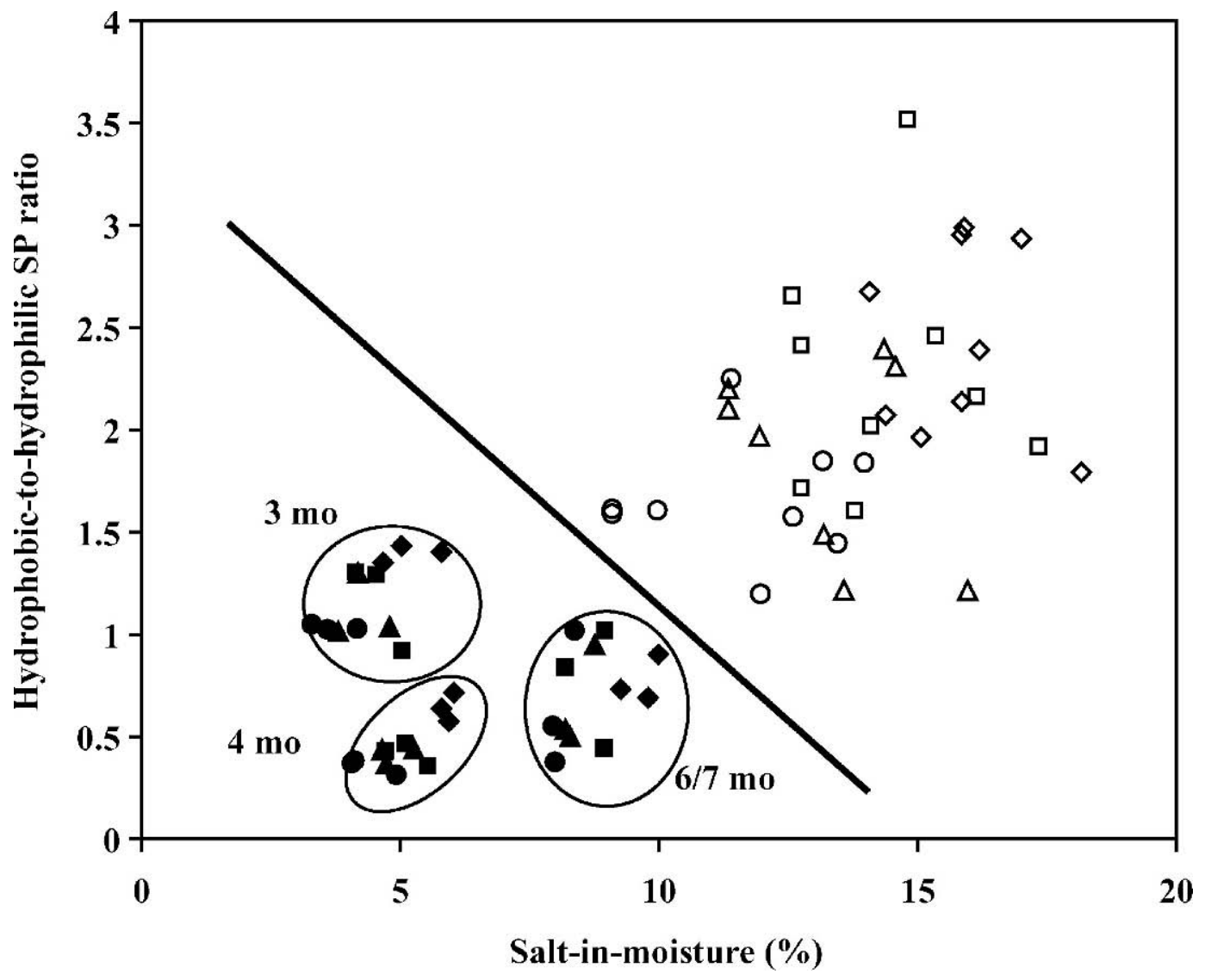

Figure 5. The distribution of selected layers ( $\diamond=$ rind, $\square \mathbf{\square}=$ external, $\Delta \boldsymbol{\Lambda}=$ middle, $\bigcirc \bullet=$ internal) from bitter (open symbols) and Protected Denomination of Origin (closed symbols) Ragusano cheese at different ages (3, 4, 6, and 7 mo) as a function of hydrophobic-tohydrophilic soluble peptides (HHSP) ratios and salt-in-moisture levels in cheese by logistic partial least squares regression.

in the rinds of Ragusano cheeses was fundamentally different from that in the rest of the cheese, as previously reported (Fallico et al., 2004). Component PC2 was equally efficient in separating PDO from bitter cheeses as PC1 was in separating rinds from other layers. Variables with high loadings on this secondary axis included salt, S/M, TCASN/pH4.6SN ratios (negative loading) and hydrophobic-to-hydrophilic soluble peptides (HHSP) ratios. Those that loaded positively were associated with bitter cheeses, which predictably had higher salt and S/M contents, leading to lower rates of secondary proteolysis than had PDO cheeses.

The efficient separation of PDO and bitter cheeses by principal components analysis and univariate analyses suggested the existence of one or more mathematical models that would predict quality category. Ordinary logistic regression was applied separately to each of the dependent chemical, FAA, HHSP, and HHIP ratio measures in an attempt to model the probability that a sample belonged to the PDO category. Although a few of these variables were highly efficient in modeling PDO status (e.g., S/M led to a $94 \%$ correct classifi- cation at the 50\% probability level and an area under Response Operator Curve $=0.995$ ), none were individually able to model perfectly the differences between quality categories. Logistic partial least squares regression, described by Bastien et al. (2005), was next applied to selected binary combinations of dependent variables having high PC2 factor loadings in the principal components analysis solution. Most of these combinations led to complete sample separation (i.e., maximum likelihood estimates reduced to zero). The model consisting of the combination of S/M and HHSP ratios resulted in the highest max-rescaled $\mathrm{R}^{2}(0.995)$ in the fewest number of iterations (6) and was thus chosen as the most representative model for these data. Unsurprisingly, these 2 variables were among the 3 having the highest $\mathrm{PC} 2$ rotated factor loadings.

Samples are plotted in Figure 5 as a function of the 2 dependent variables along with the linear function derived from logistic partial least squares regression $\left(t_{1}\right)$ associated with a $50 \%$ probability of a sample belonging to the PDO category. The line described by $t_{1}$ $[3.38 ; 0.22 ; 1]$ is a construct derived from the ordinary 
logistic regression coefficients associated with $\mathrm{S} / \mathrm{M}$ and HHSP; $t_{1}$ as a variable may therefore be derived for any sample using:

$$
\mathrm{t}_{1}=0.219(\mathrm{~S} / \mathrm{M})+0.976(\mathrm{HHSP})
$$

The variable $t_{1}$ in turn has a linear relationship with the logit of the probability that a sample belongs to the PDO category $[\operatorname{logit}(\mathrm{p})]$, which may described as:

$$
\begin{gathered}
\operatorname{logit}(p)= \\
\left.26.634-8.066\left(\mathrm{t}_{1}\right) \text { [max-rescaled } \mathrm{R}^{2}=0.995\right]
\end{gathered}
$$

Finally, according to the generalized linear model, the actual probability that a sample belongs to the PDO category (Pr) may be derived from its logit as:

$$
\operatorname{Pr}=\{1+\exp [-\operatorname{logit}(p)]\}^{-1}
$$

whose inverse is given by:

$$
\operatorname{logit}(p)=\ln \left(\frac{\operatorname{Pr}}{1-\operatorname{Pr}}\right)
$$

The above model correctly classified all samples at the very conservative probability level of 0.8 . Applying the mathematical logic described above we find:

$$
\begin{gathered}
\operatorname{logit}(p)=\ln \left(\frac{0.8}{1-0.8}\right)=\ln (4)= \\
1.386=26.634-8.066\left(t_{1}\right) \\
\mathrm{t}_{1}=3.130
\end{gathered}
$$

Any sample having a $t_{1}$ score of 3.13 or less has an $80 \%$ or greater probability of being classified as PDO. All of the PDO samples had $t_{1}$ scores less than this value. The PDO cheeses tended to cluster as a function of ripening time on the $\mathrm{S} / \mathrm{M} \times \mathrm{HHSP}$ plot. Low $\mathrm{t}_{1}$ scores in PDO cheeses ripened for 3 and 4 mo were mainly a function of their low S/M contents. Cheeses ripened for $3 \mathrm{mo}$ had high HHSP ratios relative to the other PDO cheeses, but the fact that these ratios remained less than 1.5 in all samples, along with $\mathrm{S} / \mathrm{M}$ contents averaging about $5 \%$, contributed to their relatively low $t_{1}$ scores. On the other hand, PDO cheeses ripened for 6 and $7 \mathrm{mo}$ had higher S/M contents and therefore had low $t_{1}$ scores, mainly as a function of their low HHSP ratios, which were $<1$ in nearly all samples.

Bitter cheeses did not separate into ripening timerelated clusters. Rather these cheeses separated by layer relative to the $t_{1}$ axis, with the internal layers having the highest probabilities of being PDO and the rinds having the lowest probabilities. No bitter sample attained a PDO probability greater than $20 \%$. There was a very small amount of overlap between bitter and $\mathrm{PDO}$ samples on the S/M axis. Three bitter samples (all internal layers) shared the same range as 6- and 7mo ripened $\mathrm{PDO}$ cheeses at about $10 \% \mathrm{~S} / \mathrm{M}$. A similar amount of overlap occurred on the HHSP ratio axis. Five bitter samples had ratios less than 1.5 and thus shared the same range as 3-mo ripened PDO cheeses. The typical bitter cheese had a hydrophobic-to-hydrophilic ESN ratio greater than 1.5 and an S/M content greater than $10 \%$. A cheese with exactly these characteristics would have a $t_{1}$ score of 3.654 and only a $5.5 \%$ probability of belonging to the PDO category. Cheeses with higher proportions of hydrophobic ESN or higher $\mathrm{S} / \mathrm{M}$ contents, which includes most of the bitter samples, would have even smaller probabilities. Therefore, to be classified as PDO according to this model, a cheese must have a low or equal proportion of hydrophobic ESN relative to hydrophilic ESN and have a mid- to low-range S/M content.

All of the bitter cheeses analyzed in this study had S/M levels much greater than 5.0 and this finding seemed to be in disagreement with general reports in literature. Bitterness is thought to be rarely encountered in cheese at $\mathrm{S} / \mathrm{M}$ levels $>5.0$, whereas at values lower than this there is almost a linear relationship between $\mathrm{S} / \mathrm{M}$ and the intensity of the defect (Lawrence et al., 1983). According to the logistic model, a risk of bitterness development may exist for cheeses with a midrange (5 to $10 \%$ ) S/M content but an inadequate level of secondary proteolysis. We previously found that moisture, more than salt content, had the largest single influence on rates of proteolysis in Ragusano cheese (Fallico et al., 2004). The results of this study confirmed that moisture is a key factor regulating the extent and quality of proteolysis in cheese.

\section{CONCLUSIONS}

The occurrence of bitterness in Ragusano cheese was attributable to unbalanced levels of primary and secondary proteolysis, as is well known in dairy products (Smit et al., 2000; Sousa et al., 2001). Extensive degradation of caseins and primary peptides by proteases produced large amounts of small- and medium-sized hydrophobic peptides that were not adequately removed by peptidases of microflora and therefore accumulated in cheese, potentially contributing to its bitter taste.

The brining time and level of coagulant were probably the factors contributing to bitter flavor formation in Ragusano cheese. Excessive brining times would explain the extremely high salt and S/M contents 
found in bitter cheeses, as well as the decreased moisture contents that, via a lowering of water activity, limited the enzymatic activities of microflora (Kristiansen et al., 1999), and resulted in lower rates of secondary proteolysis. Although the salt concentration in bitter cheeses was very unfavorable for chymosininduced proteolysis, caseins were almost degraded, with the large production of peptides attributable to rennet activity. A larger than appropriate amount of coagulant seemed to have been used for cheese renneting, giving rise to a slow but gradual accumulation of hydrophobic peptides and thus resulting in threshold values for bitter perception to be exceeded. Chymosin plays a major role on the release of bitter peptides from the very hydrophobic regions of caseins; therefore, the amount of rennet included in the cheese curd is thought to be directly related to bitterness development in cheese (Visser, 1993).

Although it is difficult to argue about cheeses of unknown origin with respect to their manufacturing process, our suggestions concerning brining times and levels of coagulant in bitter cheeses directly point toward a low quality of the starting milk. This probably reduced milk response to coagulation, forcing cheese makers to use larger amounts of coagulant than required. Moreover, poor milk hygiene and other problems at the production level are normally alleviated at the farm by increasing the brining times, generally a simple solution for farmers attempting to prevent cheese defects. However, the open, dry, and crumbly texture of bitter cheeses demonstrated that increasing brining times does not necessarily prevent textural and taste defects, both of which limit consumer acceptance and reduce product marketability. Results from this comparative study provided further indication about the requirement for performing good practices at farm. Maintaining proper hygiene and storage conditions of milk may result in minimizing bacterial contaminations, such as those of psychrotrophic bacteria that have been implicated in the development of bitterness in Cheddar cheese (Hicks et al., 1986). Following basic rules at the farm might result in obtaining good quality starting milk and could remove some of the likely sources of bitterness development in Ragusano cheese.

\section{ACKNOWLEDGMENTS}

The authors thank Gina DiRosa, Giovanni Farina, and Glenda Leto for technical assistance in cheese analysis. Financial support was provided by Assessorato Agricoltura e Foreste della Regione Siciliana, Palermo, Italy.

\section{REFERENCES}

Andrews, A. T. 1983. Proteinases in normal bovine milk and their action on the caseins. J. Dairy Res. 50:45-55.

Association of Official Analytical Chemists. 2000. Official Methods of Analysis. 17th ed. AOAC, Gaithersburg, MD.

Bastien, P., V. Esposito Vinzi, and M. Tenenhaus. 2005. PLS generalised linear regression. Comput. Stat. Data Anal. 48:17-46.

Blakesley, R. W., and J. A. Boezi. 1977. A new staining technique for proteins in polyacrylamide gels using Coomassie Brilliant Blue G250. Anal. Biochem. 82:580-581.

Broadbent, J. R., M. Barnes, C. Brennand, M. Strickland, K. Houck, M. E. Johnson, and J. L. Steele. 2002. Contribution of Lactococcus cell envelope proteinase specificity to peptide accumulation and bitterness in reduced-fat Cheddar cheese. Appl. Environ. Microbiol. 68:1778-1785.

Bynum, D. G., and D. M. Barbano. 1985. Whole milk reverse osmosis retentates for Cheddar cheese manufacture: Chemical changes during aging. J. Dairy Sci. 68:1-10.

Carpino, S., S. Mallia, S. La Terra, C. Melilli, G. Licitra, T. E. Acree, D. M. Barbano, and P. J. Van Soest. 2004. Composition and aroma compounds of Ragusano cheese: Native pasture and total mixed rations. J. Dairy Sci. 87:816-830.

Carrera, E., P. Gaya, M. Medina, and M. Nunez. 1999. Effect of milk coagulant on the formation of hydrophobic and hydrophilic peptides during the manufacture of cows' milk Hispànico cheese. Milchwissenschaft 54:146-148.

Cliffe, A. J., J. D. Marks, and F. Mulholland. 1993. Isolation and characterization of non-volatile flavours from cheese: Peptide profile of flavour fractions from Cheddar cheese, determined by reversed-phase high performance liquid chromatography. Int. Dairy J. 3:379-387.

Creamer, L. K. 1985. Water absorption by renneted casein micelles. Milchwissenschaft 40:589-591.

Edwards, J. L., Jr., and F. V. Kosikowski. 1983. Bitter compounds from Cheddar cheese. J. Dairy Sci. 66:727-734.

Engel, E., C. Septier, N. Leconte, C. Salles, and J. L. le Quere. 2001. Determination of taste-active compounds of a bitter Camembert cheese by omission tests. J. Dairy Res. 68:675-688.

Engels, W. J. M., and S. Visser. 1994. Isolation and comparative characterization of components that contribute to the flavour of different cheese types. Neth. Milk Dairy J. 48:127-140.

Fallico, V., L. Chianese, S. Carpino, and G. Licitra. 2003b. Aspetti qualitativi e quantitativi della proteolisi nel corso della stagionatura del formaggio Ragusano. Sci. Tecn. Latt.-Cas. 54:117-141.

Fallico, V., L. Chianese, J. Horne, S. Carpino, and G. Licitra. 2003a. Influence of feeding strategy (pasture vs. TMR) on proteolysis in Ragusano cheese during ripening. J. Dairy Sci. 86(Suppl. 1):367. (Abstr.)

Fallico, V., P. L. H. McSweeney, K. J. Siebert, J. Horne, S. Carpino, and G. Licitra. 2004. Chemometric analysis of proteolysis during ripening of Ragusano cheese. J. Dairy Sci. 87:3138-3152.

Fenelon, M. A., P. O'Connor, and T. P. Guinee. 2000. The effect of fat content on the microbiology and proteolysis in Cheddar cheese during ripening. J. Dairy Sci. 83:2173-2183.

Fox, P. F., J. Law, P. L. H. McSweeney, and J. Wallace. 1993. Biochemistry of cheese ripening. Pages 389-438 in Cheese: Chemistry, Physics and Microbiology. Vol. 1. P. F. Fox, ed. Chapman and Hall, London, UK.

Fox, P. F., and P. L. H. McSweeney. 1996. Proteolysis in cheese during ripening. Food Rev. Int. 12:457-509.

Fox, P. F., and B. F. Walley. 1971. Influence of sodium chloride on the proteolysis of casein by rennet and by pepsin. J. Dairy Res. 38:165-170.

Gazzetta Ufficiale della Comunità Europea. 1996. No. 1263. July 1, 1996. Registrazione delle indicazioni geografiche e della denominazioni di origine nel quadro della procedura di cui all'articolo 17 del Reg. to CEE no. 2081/92. European Community, Brussels, Belgium.

Gobbetti, M., R. Burzigotti, E. Smacchi, A. Corsetti, and M. De Angelis. 1997. Microbiology and biochemistry of Gorgonzola cheese during ripening. Int. Dairy J. 7:519-529. 
Gomez, M. J., S. Garde, P. Gaya, M. Medina, and M. Nunez. 1997. Relationship between level of hydrophobic peptides and bitterness in cheese made from pasteurized and raw milk. J. Dairy Res. 64:289-297.

Gonzalez de Llano, D., M. C. Polo, and M. Ramos. 1995. Study of proteolysis in artisanal cheeses: High performance liquid chromatography of peptides. J. Dairy Sci. 78:1018-1024.

Guinee, T. P., and P. F. Fox. 1984. Studies on Romano-type cheese: General proteolysis. Ir. J. Food Sci. Technol. 8:105-114.

Habibi-Najafi, M. B., and B. H. Lee. 1996. Bitterness in cheese: A review. Crit. Rev. Food Sci. Nutr. 36:397-411.

Hicks, C. L., C. Onvorah, J. O'Leary, and B. E. Langlois. 1986. Effect of milk quality and low temperature storage on cheese yield. J. Dairy Sci. 69:649-657.

International Dairy Federation. 1993. Standard Method 20B: Milk. Determination of nitrogen content. International Dairy Federation, Brussels, Belgium.

International Dairy Federation. 1997. Standard Method 152A: Milk and milk products. Determination of fat content (general guidance on the use of butyrometric methods). International Dairy Federation, Brussels, Belgium.

Kelly, M., P. F. Fox, and P. L. H. McSweeney. 1996. Effect of saltin-moisture on proteolysis in Cheddar-type cheese. Milchwissenschaft 51:498-501.

Kristiansen, K. R., A. S. Deding, D. F. Jensen, Y. Ardö, and K. B. Qvist. 1999. Influence of salt content on ripening of semi-hard round-eyed cheese of Danbo-type. Milchwissenschaft 54:19-23.

Kuchroo, C. N., and P. F. Fox. 1982. Soluble nitrogen in Cheddar cheese: Comparison of extraction procedures. Milchwissenschaft 37:331-335

Lau, K. Y., D. M. Barbano, and R. R. Rasmussen. 1991. Influence of pasteurization of milk on protein breakdown in Cheddar cheese during aging. J. Dairy Sci. 74:727-740.

Lawrence, R. C., J. Gilles, and L. K. Creamer. 1983. The relationship between cheese texture and flavour. N.Z. J. Dairy Sci. Technol. 18:175-190.

Lee, K. D., C. G. Lo, and J. J. Wartheson. 1996. Removal of bitterness from the bitter peptides extracted from Cheddar cheese with peptidases from Lactococcus lactis ssp. cremoris SK11. J. Dairy Sci. 79:1521-1528.

Lemieux, L., R. Puchades, and R. E. Simard. 1989. Size-exclusion HPLC separation of bitter and astringent fractions from Cheddar cheese made with added Lactobacillus strains to accelerate ripening. J. Food Sci. 54:1234-1237.

Licitra, G., P. Campo, M. Manenti, G. Portelli, S. Scuderi, S. Carpino, and D. M. Barbano. 2000. Composition of Ragusano cheese during aging. J. Dairy Sci. 83:404-411.

Lynch, C. M., P. L. H. McSweeney, P. F. Fox, T. M. Cogan, and F. B. Drinan. 1996. Manufacture of Cheddar cheese with and without adjunct lactobacilli under controlled microbiological conditions. Int. Dairy J. 6:851-867.

Mayer, H. K. 2001. Bitterness in processed cheese caused by an overdose of a specific emulsifying agent? Int. Dairy J. 11:533542.

McSweeney, P. L. H., N. F. Olson, P. F. Fox, A. Healy, and P. Hojrup. 1993. Proteolytic specificity of chymosin on bovine $\alpha$ s1-casein. J. Dairy Res. 60:401-412.

Molina, E., M. Ramos, L. Alonso, and R. Lopez-Fandino. 1999. Contribution of low molecular weight water-soluble compounds to the taste of cheeses made of cows', ewes', and goats' milk. Int. Dairy J. 9:613-621.

Mulvihill, D. M., and P. F. Fox. 1979. Proteolytic specificity of chymosin on bovine $\alpha$ s1-casein. J. Dairy Res. 46:641-651.

Smit, G., A. Verheul, R. van Kranenburg, E. Ayad, R. Siezen, and W. Engels. 2000. Cheese flavour development by enzymatic conversions of peptides and amino acids. Food Res. Int. 33:153-160.

Sousa, M. J., Y. Ardö, and P. L. H. McSweeney. 2001. Advances in the study of proteolysis during cheese ripening. Int. Dairy J. 11:327-345.

van Kranenburg, R., M. Kleerebezem, J. Van Hylckama Vlieg, B. M. Ursing, J. Boekhorst, B. A. Smit, E. H. E. Ayad, G. Smit, and R. J. Siezen. 2002. Flavour formation from amino acids by lactic acid bacteria: Predictions from genome sequence analysis. Int. Dairy J. 12:111-121.

Visser, S. 1993. Proteolytic enzymes and their relation to cheese ripening and flavor: An overview. J. Dairy Sci. 76:329-350. 